\section{Congress to abandon ship?}

\section{Washington}

THE outlook for the proposed US space station Freedom looks bleak after a showdown last week between officials from the National Aeronautics and Space Administration (NASA) and members of the US House of Representatives Committee on Science, Space and Technology. The committee's support has been crucial in winning funds for the space station from a budget-conscious Congress, but now chairman Robert Roe (Democrat - New Jersey), furious at NASA over its plans to scale down the project, is threatening to propose scrapping the whole project.

Under the new plan, which was prompted by an anticipated 20 per cent cut in the space station's 1990 budget, NASA would begin construction of the space station in March 1995, but would stretch out assembly over an extra year and a half, causing delays in the schedule for attaching the European and Japanese modules. As well as delays in achieving full power capacity and in installing the full quota of crew members, there would be permanent

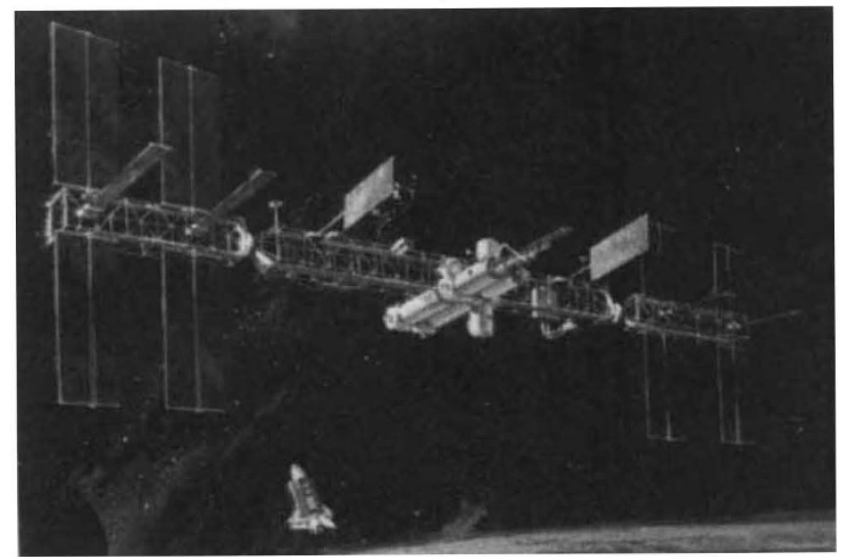

Nelson (Democrat-Florida) complained that there had been 11 major reviews of the space station programme in the last five years, partly because of the high turnover in management. During that time there have been four NASA administrators, five associate administrators and six programme directors.

Criticism of NASA's new plans from both the Japanese National Space Development Agency and the European Space Agency, has fuelled fears that this instability would jeopardise future inter national collaboration in space. Roe said that the credibility of the United States as well as the future of the space station "is on the line". A Japanese Diet member told committee member Jack Buechner (Republican - Missouri) that if the United States makes any more changes in the space station they are "going to pick up their yen and go home". But Truly maintained that the international partners were included from the beginning in formulating the new plans and that most of their complaints have been dealt with.

Further changes in the space station could also delay President Bush's proposed missions to the Moon and to Mars. If the space station is to be used as a base for developing an outpost on the Moon, it will need greater power capacity and room for more than the eight astronauts planned. Congress will be hard-pressed to provide the large increase in funds needed if NASA is to support both Vincent de Fate's artistic view of how the space station should look. the Moon/Mars initiative changes, such as the abandoning of plans for a new high-pressure space suit. But the associate administrator for the space station, William Lenoir, said at the hearing that many of the changes were made for technical reasons. For example, proposals for "hooks and scars" needed if the space station is to service other spacecraft have not been finalized because of insufficient technical understanding of what will be required of them. Lenoir insisted that the space station would remain essentially as planned.

Rejecting this claim, the committee accused NASA of making "draconian" changes without consulting Congress or the international partners. An irate Roe bellowed at NASA administrator Richard Truly that he would not "be made a damn fool of" by urging full financial support while NASA was reworking its plans in order to build a different low-cost, space station. The chairman of the subcommittee on space science and applications, Bill
'Merit' pay for all

\section{Barcelona}

UNIVERSITY researchers in Spain may be able to increase their salaries by up to 50 per cent by the end of their career if they can demonstrate "productivity" in teaching or research. Although this news, the consequence of a government decree made in September, has in general produced satisfaction in the universities, it infuriated researchers working for the Science Research Council (CSIC), who were excluded from the scheme and felt that they were being discriminated against. But now the CSIC has announced a similar initiative.

Salaries in Spanish universities and research institutions have always been very low compared to those in private industry, and the difference has been growing as the country's economy has improved. Compared to France, for example, salaries in Spain are similar at the beginning of the career but then progress very little, making the disparity for senior researchers very apparent. On top of this, Spain has now an annual rate of inflation of nearly 7 per cent, but salaries have increased only 3 per cent this year.

In an attempt to alleviate the problem, and to stimulate the quality of research in the universities, the government has decided to introduce a "productivity" bonus that could increase by up to 10 per cent every five years the salary of any researcher or lecturer who can show excellence in teaching or research.

Quality of teaching will be assessed by the universities, some of which have already decided to give maximum scores to everyone, and research achievement will be judged by national commissions.

Traditionally, the salaries of CSIC researchers have risen in parallel with those of university scientists, a system that led to collaboration and exchange of personnel between the two groups. But CSIC researchers were angered by not being offered a comparable productivity bonus, and feared that the omission was part of an unofficial policy to divert CSIC towards applied research and collaboration with industry. The last round of new positions created in CSIC in fact emphasized applied research, even though some of the best groups in CSIC work in basic areas of biology and physics. The controversy led to the unusual sight of scientists in laboratory coats picketing the CSIC building in Madrid.

The president of CSIC has now announced that efforts are being made to give CSIC researchers a similar career structure to their university counterparts, and to encourage further collaboration.

Pedro Puigdomenech 